\title{
EL ENFADO DE LAS NIÑAS. NOTAS PARA CONVERTIR EL ENFADO EN LUCIDEZ ${ }^{1}$
}

Mariasun LANDA ETXEBESTE

Escritora malanda.ml@gmail.com

\section{Resumen}

Partiendo del deseo a favor de una literatura infantil y juvenil no sexista, la autora se interroga a sí misma por la forma en que la propia creatividad y libertad del autor/a puede conjugarse con las buenas intenciones, un cierto proteccionismo y hasta cierta censura que ha impuesto la corrección política ante este tema. Si se puede hacer una literatura no sexista en una sociedad que sigue siéndolo, sin que se cree un desfase entre la realidad y la ficción. Y recuerda, aludiendo a tres autoras referenciales para ella (Simone de Beauvoir, Virginia Woolf y Astrid Lindgren) que el escritor/a debe escribir desde su imaginario personal y su libertad creativa. No puede renunciar a ella porque la literatura vehicula su necesidad de autoconocimiento, expresión y comunicación.

Palabras clave: literatura no sexista, enfado, corrección política, lucidez, libertad creativa.

\section{LA COLÈRE DES FILLES. NOTES POUR TRANSFORMER LA COLÈRE EN LUCIDITÈ}

\section{Résumé:}

Partant du désir d'une littérature non sexiste pour enfants et jeunes, l'auteure s'interroge sur la manière dont la créativité et la liberté de l'auteur/e peuvent être associées à de bonnes intentions, à un

1 Algunos fragmentos de estas páginas forman parte de la conferencia impartida y publicada con motivo del $32^{\circ}$ Congreso Internacional de IBBY. Santiago de Compostela 2010. 


\section{Mariasu Landa Etxebeste}

certain protectionnisme et même à une certaine censure qui a imposé le politiquement correct sur cette question. Si on peut créer une littérature non sexiste dans une société qui l'est toujours, sans créer un décalage entre la réalité et la fiction. Et elle nous rappelle, faisant allusion à trois auteures de référence pour elle (Simone de Beauvoir, Virginie Woolf et Astrid Lindgren), que l'écrivain/e doit écrire depuis son imaginaire personnel et sa liberté de création. L'écrivain ne peut pas l'abandonner parce que la littérature traduit son besoin de connaissance de soi, d'expression et de communication.

Mots-clés: littérature non sexiste, colère, politiquement correct, lucidité, liberté de création.

\section{THE GIRLS'ANGER}

\section{THOUGHTS ON TURNING ANGER INTO CLARITY}

\section{Abstract}

Stemming from the desire to support a non-sexist literature for children and young adults, the author wonders about the way in which one's creativity and freedom can be combined with good intentions, a certain degree of protectionism, and even some level of censorship, which has been imposed on this topic by political correctness. Whether a gender sensitive literature can be produced in a society that is still sexist, without creating a gap between reality and fiction. She also reminds us, referring to three benchmarking woman authors (Simone de Beauvoir, Virginia Woolf y Astrid Lindgren), that authors should write from their own personal imaginary and creative freedom. Authors may not give them up because literature conveys their need of self-awareness/self-knowledge, expression and communication.

Key words: non-sexist literature, outrage, political correctness, lucidity, creative freedom.

Recuerdo que, cuando comencé a publicar Literatura infantil y juvenil por los años 80, me escandalizaban las pocas protagonistas femeninas en los libros para niños y niñas. Además, ese protagonismo era a menudo muy cuestionable desde el punto de vista de la defensa de unos valores de autonomía, igualdad y libertad en los que yo creía. En cierta forma, participé en ese movimiento de un colectivo amplio de la sociedad, de mujeres, docentes, bibliotecari@s que quiso 1levar a la literatura 
El enfado de las niñas. Notas para convertir el enfado en lucidez

infantil y juvenil nuevos valores progresistas; una literatura infantil alternativa, que combatiera todo aquello que era discriminatorio para las mujeres. Ofrecer el protagonismo a las niñas y un divertido juego de cambios de roles marcaron aquella etapa donde la colección de álbumes de "A favor de las niñas" de Adela Turin fue un verdadero hito que sigue estando vigente hoy en día. Mirando hacia atrás, en mi producción literaria aquella fue una etapa gozosa, casi fácil, aunque supongo que novedosa para la época ya que acabé harta de tener que dar explicaciones. En todas las entrevistas que me hacían, me preguntaban el por qué abundaban tanto en mis libros las protagonistas femeninas, algo que jamás se les pedía a otros escritores cuyos libros tenían protagonistas masculinos.

Creo que hoy en día, las niñas han dejado de ser minoría en la literatura infantil. Quizás a ello ha contribuido también el hecho de que los libros de mayor éxito y difusión de los últimos años son, mayoritariamente, obra de mujeres (Rowling, Meyer, Funke, Dragt, Collins, Santos), y en ellos se advierte una especial relevancia de los personajes femeninos y un mayor cuidado en su construcción. Lo cual no quiere decir que tengamos ya un nuevo modelo femenino que haya superado al anterior.

Personalmente, en mi caso, he de mencionar el libro con el que di el paso de dejar hablar a las niñas. Me refiero a Iholdi (Erein, 1992), ilustrado por Asun Balzola. Y allí me encontré con el enfado, con el desconcierto y con la voz femenina infantil, que era una forma de ir más allá de la inversión de roles. Porque, para entonces, algo ya me inquietaba.... Aún compartiendo aquellas buenas intenciones, la profusión de protagonistas piratas, futbolistas, brujas sabias, princesas superdotadas y lobos buenos, la inversión de roles, la idealización del mundo femenino, el carácter utópico y un poco maniqueísta de ciertas obras me desazonaba.

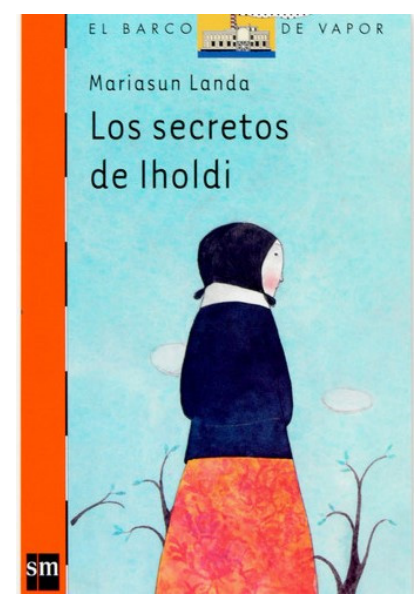

Fig. 1 Los secretos de Iholdi

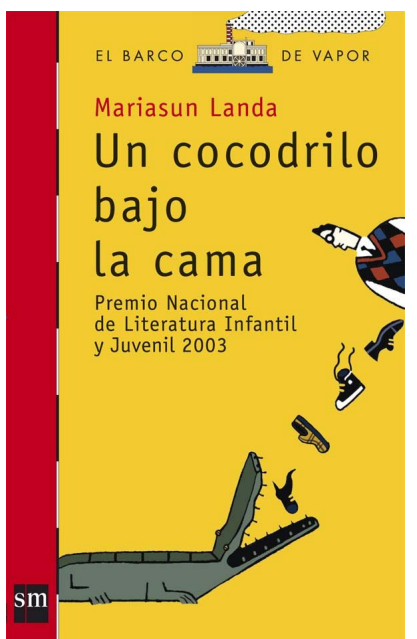

Fig. 2 Un cocodrilo bajo la cama 


\title{
Mariasu Landa Etxebeste
}

Permítanme que reproduzca unos textos de esta niña Iholdi:

La diligencia

Hoy hemos estado jugando en el viejo coche abandonado que está en nuestra calle.

Pello y los otros han propuesto que jugásemos a los indios y que el coche viejo fuera una diligencia.

Que las chicas nos metiéramos dentro y que ellos nos atacarían...

-Y luego, ¿qué?

- Vosotras, cuando veáis a los indios, os desmayáis...

Y así lo hemos hecho.

Después yo he dicho que por qué no lo hacíamos al revés y Pello ha dicho que no. Que los chicos no se desmayaban. Y nosotras nos hemos enfadado, porque queríamos hacer de indios y a ellos les tocaba estar en la diligencia.

A final han dicho que bueno, que sí. Pero cuando los hemos atacado, han abierto las puertas y nos han respondido a tiros. Ninguno se ha desmayado y las chicas nos hemos vuelto a enfadar.

Con los chicos no se puede jugar.

\author{
Quique \\ No entiendo a Quique. \\ Cuando jugamos en el portal de casa es de lo más \\ majo. Nos llevamos muy bien y me deja comics para \\ leer. Le gusta mucho nadar y a mí también. Muchas \\ veces vamos juntos a la playa, pero si allá se \\ encuentra con alguno de su clase, de repente, se aleja \\ de mí, me echa arena y me hace todo tipo de \\ barrabasadas en el agua. Y yo, enfadada, me vuelvo \\ sola a casa. \\ Pero al día siguiente, me ofrece otro comic. Como si \\ no hubiera pasado nada...
}

No le entiendo.

Es evidente que la chiquilla estaba enfadada. Yo también lo estaba cuando tenía su edad y creo que con toda razón. Para empezar, tuve que esperar a ir a la universidad para tener chicos compañeros de clase. Mi educación fue la propia de un colegio religioso, en pleno franquismo, donde reinaba una atmósfera retrógrada y represiva. La lectura me proporcionaba una ventana para huir, para soñar, pero no me podía identificar con los personajes femeninos que a menudo encontraba: niñas pacientes, pasivas, sumisas... princesas indolentes, tontas y sobre todo sosas, muy sosas.

Sí, debía estar muy enfadada porque robaba a mi hermano sus libros de aventuras, de intriga, de emoción, protagonizados por unos chicos de los que me prendaba como si de novios se trataran. ¡Qué rocambolesco camino psicológico tuvimos que hacer las niñas de mi generación, educadas en 
El enfado de las niñas. Notas para convertir el enfado en lucidez

colegios religiosos, no mixtos, para identificarnos con los chicos que nunca seríamos y queriendo ser distintas de los modelos femeninos que se nos inculcaban! No fui nada original: yo también, de aquellas “mujercitas” de L.M.Alcott, elegí a Jo, que además quería ser escritora como yo. Pero hace tiempo que Iholdi se hizo mayor. Ella, como Wendy, también decidió crecer y me pregunto si seguirá enfadada.

Me pregunto qué tal le fue con aquellos chicos que eran compañeros de clase, convertidos ya en hombres. Cómo le habrá ido en el mundo laboral, si sufre precariedad y brecha salarial por ser mujer. Si se escandaliza con la violencia de género, si es sensible a las reivindicaciones del colectivo LGTBI. Si cree que sus compañeros actuales tienen una nueva forma de relacionarse con las mujeres y otra forma de vivir y expresar los sentimientos. Si piensa que, en muchos lugares, sigue siendo un handicap nacer mujer, un riesgo injusto, y que, en nuestro entorno, bajo la apariencia de la igualdad entre los sexos se dan escandalosas discriminaciones laborales, sociales, culturales...

O Iholdi quizás piensa, como algunas jóvenes universitarias alumnas de mis clases, que no existe ninguna discriminación, que eso del feminismo es algo anticuado y rancio, olvidando que su situación actual es una conquista, el resultado de una larga lucha por la dignidad de la mujer.

No lo sé.

Por mi parte, debo confesar que, a veces, sigo estando muy enfadada y casi siempre preocupada con el tema del sexismo en la sociedad y en la literatura en particular. Porque aunque el papel que la mujer desempeña en nuestra sociedad ha evolucionado mucho, casi podríamos decir que ha sido espectacular, todavía los modelos femeninos y masculinos que se presentan en los libros, los comics, y todo el resto de manifestaciones culturales que se dirigen al público infantil y juvenil, continúan anclados en estereotipos sexistas. Quizás no de una forma tan burda como ocurría cuando Iholdi era niña sino de forma más sutil, esa falsa creación de nuevos estereotipos sexuales que son los de siempre pero presentados bajo un nuevo maquillaje (Chick literatura) Porque la educación mixta es un hecho en todos los niveles educativos, pero la primacía de los valores masculinos no es cuestionada, las mujeres y las niñas deben hacerlos suyos, el universo femenino sigue siendo de segunda categoría. 


\section{Mariasu Landa Etxebeste}

Es por eso y porque el enfado es fructífero si no se convierte en amargura me propongo formular algunas convicciones: siento que la buena literatura no siempre es la que se hace con buenas razones, con contenidos progresistas fijados de antemano. Intuitivamente, guardo mis convicciones feministas para artículos u otras manifestaciones no literarias, incluidos los compromisos políticos o educativos. La literatura era y es para mí otra cosa.

Recuerdo la alarma que suscitó en mí el extracto de un libro, Fuera moldes, que me pasaron:

\section{Cómo escribir un cuento no sexista,}

En aquel resumen adaptado se nos indicaban las características que debían tener nuestros libros si no querían ser sexistas:

-La distribución equitativa de personajes femeninos y masculinos que afectaba a títulos, citas e ilustraciones.

-La distribución equitativa de los distintos roles desempeñados por las mujeres y los hombres en el cuento.

-La distribución equitativa de los rasgos positivos y negativos en dichos roles.

-Las normas sobre el aspecto físico y manera de vestir de los personajes.

-Normas sobre sus cualidades y defectos intelectuales.

-Normas sobre sus cualidades y defectos afectivos

-Normas sobre sus cualidades y efectos volitivos

-Y cómo evitar el sexismo en el vocabulario, en la gramática y en la sintaxis.

Quiero pensar que la asfixia y fastidio que sentí se debían en parte al hecho de tratarse de un extracto torpe y dogmático. Aquello nada tenía que ver con la literatura.

Es desalentador que parte de nuestros planteamientos de los años 70 y 80 hayan desembocado en la llamada corrección política, un cierto fundamentalismo que ha promocionado una literatura plana, que evita los conflictos, que ejerce de censura, consecuencia, quizás, de una mala interpretación de la función pedagógica de la literatura. Ha habido autores que han denunciado la presión editorial al respecto, el miedo a escribir lo que imaginan, en una palabra: la falta de libertad. Tanto proteccionismo no es adecuado, no es compatible con el mundo de la creación. ¿Cuando escribimos literatura no 
El enfado de las niñas. Notas para convertir el enfado en lucidez

estamos poniendo en juego algo muy personal, algo de nuestro ser más profundo? ¿Se puede imponer el no sexismo con teorías desde fuera?

-Me pregunto si en una sociedad sexista y patriarcal puede escribirse una literatura que no lo sea y hasta qué punto... sin que haya un gran desfase, sin que la ficción vaya por delante de los avances sociales, sin escribir, al fin y al cabo, un panfleto ¿No será que, sencillamente, si sigue existiendo una literatura sexista es porque la sociedad sigue siéndolo por mucho que no nos guste?

-Me pregunto si se puede escribir sobre lo que una no cree, sobre lo que no siente, lo que, en el fondo, no piensa... si una Ley de la Igualdad puede solucionarlo. ¿Bastan las buenas intenciones?

- Me pregunto dónde está la libertad creativa, la necesidad de expresión y comunicación del autor/a de LIJ, su universo personal, su libertad en resumidas cuentas ¿Basta a un escritor de LIJ con tener muy claros los valores que quiere transmitir, la función pedagógica de la literatura?

E intento responder, responderme, con sinceridad...

En mi caso, eso me lleva a replantearme qué es ser escritor/a en general y escritor/a de Literatura Infantil y Juvenil en particular.

Quiero recordar que, entre otras cosas, esa literatura puede vehicular el mundo imaginario del autor-a, su necesidad de autoconocimiento, de expresión y comunicación. La forma que se vale de ella para adentrarse como un extraño, como un extranjero en el País de Sí Mismo. Y al afirmar esto, pienso en los grandes clásicos, en Lewis Carroll, en Antoine de Saint Exupéry, en James Barrie... A mí también la Literatura Infantil me ha ayudado a iluminar, a dar forma a aquello que ignoraba de mi misma pero que me habitaba ¿Debo permitir que alguien o algo manipule, frene o cuestione ese proceso?

Ante este cúmulo de preguntas decido llamar en mi ayuda a tres voces sabias, voces amigas, tres damas admiradas de la literatura: Simone de Beauvoir, Virginia Woolf y Astrid Lindgren. Están acostumbradas a que las convoque a este tipo de encuentros; comenzamos tomando un té y a veces terminamos con un gintonic.

Simone de Beauvoir (1967) me recuerda que la mujer no nace sino que se hace. Echa por tierra la idea del patriarcado de que existe una esencia femenina. Que una cosa es ser biológicamente macho o hembra y otra el género, masculino/femenino, que es algo que se aprende, algo cultural e ideológico. Así pues, el género es el conjunto de normas diferenciadas para cada sexo que son elaboradas por 


\section{Mariasu Landa Etxebeste}

la sociedad según sus necesidades e impuestas a los individuos desde que nacen como modelo de identificación. De ahí se derivan los roles sexuales que serían el conjunto de tareas y funciones derivadas del género y atribuidas al sexo como propio al mismo.

Ante el tema de este artículo Simone de Beauvoir y yo estamos de acuerdo que el enemigo número uno es el estereotipo: esa idea que se repite y se reproduce sin variación, esa imagen uniformada común a los miembros de un grupo que no recoge las características individuales, que representa una idea generalizada que se impone como molde o cliché a los miembros del grupo al que se refiere, que están profundamente arraigadas hasta el punto de considerarlas como naturales y derivadas de la diferencia sexual.

El estereotipo no sólo es el instrumento del sexismo sino que es el mayor enemigo de la buena literatura, concluimos casi al unísono.

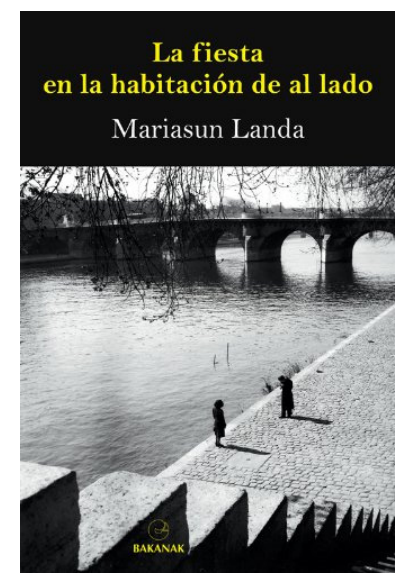

Fig. 3 La fiesta en la habitación de al lado

Virginia Woolf me recuerda que para escribir hacen falta una habitación propia y 500 libras. Sí, ya lo sabía. Un espacio y autonomía económica. Pero que al dinero y al espacio hay que añadir otro gran obstáculo: el escribir como mujer, lo cual según ella, supone, en cierta forma, olvidarse de su sexo. Sí, escribir como una mujer que ha olvidado que es mujer, insiste ella. Evitar la queja, la reivindicación, escribir a favor de cualquier causa por muy justa que sea. Hace suyas la reflexión del poeta Coleridge para el que el arte debe ser andrógino, opina que en el artista deben casarse los dos sexos, que todos tenemos algo de hombre y de mujer dentro de nosotros. Creo que ella se adelantó a las reivindicaciones LGTBI, porque para algunas personas, sentirse hombre o sentirse mujer es algo muy difuso, y cuando 
El enfado de las niñas. Notas para convertir el enfado en lucidez

se buscan a sí mismos más allá de los estereotipos femeninos o masculinos se encuentran, a menudo, con la incomprensión y rechazo de la sociedad.

Sin tener en cuenta esa androgeneidad del arte, dice Virginia Woolf, aquello que escribimos, cito literalmente, "por brillante y eficaz, poderoso y magistral que parezca un día o dos, se marchitará al anochecer" (1967, p. 43).

Y yo me sonrío, porque la alusión a las flores que se marchitan me la repetie la autora de Pipa Calzaslargas, Astrid Lindgren.

Ella también me recuerda las mismas palabras que utilizó en su delicioso libro Mi mundo perdido al dirigirse a un futuro autor de libros infantiles:

Escribe lo que te salga del alma y con ilusión. Tanto a ti como a los demás autores de obras infantiles os deseo libertad, aquella misma libertad que es natural para el literato que escribe para adultos y que le permite decir lo que quiere y como quiere. [...] piensa en tu libertad. Porque sin esa libertad, la flor de la poesía no tarda en marchitarse. Esté donde esté ( Lindgren, 1985, p.80).

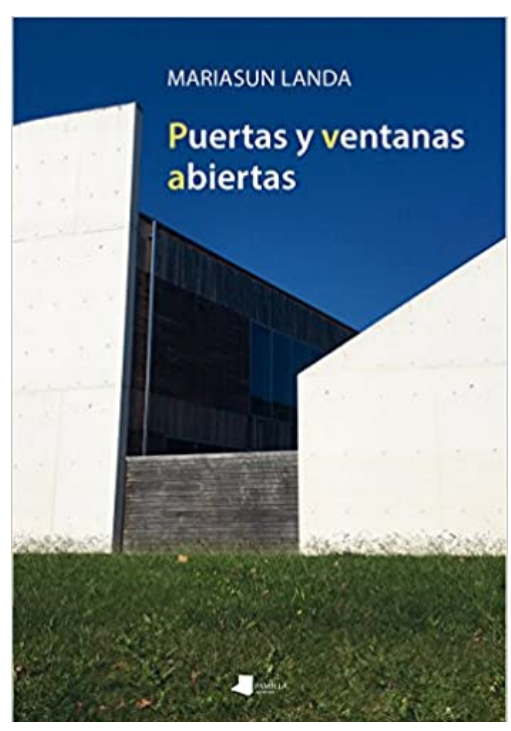

Fig. 4 Puertas y ventanas abiertas

Estas excelentes amigas siempre tienen la capacidad de serenarme, siempre les agradezco que conviertan mi enfado en un gramo de lucidez y algo de sosiego.

Así que, cuando me dispongo a cerrar mi artículo, sólo se me ocurre apuntar y ofrecer unas notas que tampoco quieren ser conclusiones ya que se trata de intercambiar ideas.

-La primera sería una constatación intuitiva. Quizás hemos sido ingenuas al pensar que unos 


\section{Mariasu Landa Etxebeste}

cambios deliberados en la producción de la LIJ a favor de las mujeres eran conquistas irreversibles. Una ideología patriarcal y sexista milenaria exige una vigilancia y una lucha constantes. Hay que convivir con ese sexismo mientras seguimos luchando contra él. El estereotipo es el peor enemigo, no sólo del feminismo sino también, y sobre todo, de la buena literatura.

-La segunda sería que la literatura en general y la infantil juvenil en particular reflejan los avances y lagunas del progreso social en la superación de la discriminación femenina de la sociedad. En este momento creo que estamos ante un momento de confusión, ya que el modelo femenino está construyéndose en un marco que sigue siendo ferozmente sexista, porque muchas mujeres y hombres están buscando, a tientas, referencias y realidades nuevas en un vaivén de avances y retrocesos.

-Y para terminar, una tercera nota: si realmente creemos en la literatura, hay que volver a afirmar que no se puede escribir sin libertad. No se puede negar al autor/a el medio de comunicación y expresión de su universo. Hay que dejar que sea libre. Animarle a ello, porque quizás es una de las causas de que lo que escriba guste también a los niños o a los jóvenes, porque no son tontos y saben cuándo un autor/a no se encoge ni se achica para hablarles. Quizás habría que confiar más en la capacidad crítica de los lectores y sus mediadores sin caer en la tentación de hacer una literatura recortada, plana, llena de buenas intenciones que ni nutren ni sugieren, sólo aburren. Flores que se marchitan enseguida.

\section{Bibliografía}

Beauvoir, S. de (1967). Le Deuxième Sexe. Vol. I Les faits et les mythes. Paris: Gallimard, (1958). Landa, M. (1988). Iholdi, Donostia /San Sebastián: Erein. Versión euskera. (2006). Iholdi, en Tres bichos raros. Madrid: SM, col. Barco de Vapor. Versión en castellano.

Lindgren, A. (1985). Mi mundo perdido. Barcelona: Juventud.

Woolf, V. (1967). Una habitación propia. Barcelona: Seix Barral.

www.mariasunlanda.net 